\title{
Vaccine Hesitancy, Vaccine Acceptance, and Recommendations about the COVID-19 Vaccines
}

\author{
Cheryl Ann Alexander ${ }^{{ }^{*}}$ | Lidong Wang ${ }^{2}$ | Vijay Shah ${ }^{3}$
}

${ }^{1}$ Institute for IT innovation and Smart Health, Mississippi, USA

${ }^{2}$ Institute for Systems Engineering Research, Mississippi State University, Mississippi, USA

${ }^{3}$ Division of Business, Accounting \& Public Services, West Virginia University at Parkersburg, USA

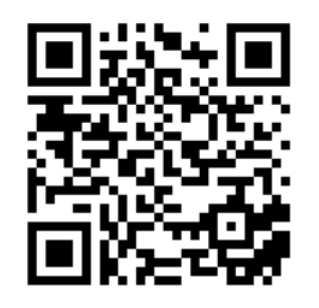

\section{Abstract}

This paper presents COVID-19 vaccines, the types of vaccine manufacturing, and SARS-CoV-2 variants and likely resistance to COVID-19 vaccines. Since the vaccines were distributed and entered the healthcare market for the general population, people have either readily accepted the vaccine or they have developed hesitancy - a term coined after the vaccines entered the healthcare market for the general population. Vaccine hesitancy refers to the uncertainty some people have about various aspects of vaccination, whether it is the manufacturing process of the drug, the personal impact of the political climate (e.g., vaccine mandates, political opinions during speeches and interviews, etc.) surrounding the vaccine, or the impact of social media (e.g., Facebook and Twitter misinformation algorithm, etc.) or the impact from media coverage, which has been less than ideal (e.g., distortion of COVID-19 facts and figures, dishonesty about the vaccine itself, promotion of one political party's agenda, misinformation related to variants, etc.). These distorted views have impacted the general public far much more than practitioners have and vaccination rates have fallen amid the chaos of the pandemic itself, the aforementioned factors, and the reduction of efficacy among vaccinated individuals leading to higher COVID-19 cases, hospitalizations, and deaths and a disparity among minorities as they are the hardest hit by COVID-19 and they have the highest rate of unvaccinated individuals, potentially related to the suspicions put in the minds of the US public by politicians during the 2020 election cycle. Public opinion has also lagged due to the rates of infection now showing in the vaccinated. Disparities still exist in vaccine administration, whether from a lack of education about the vaccine's effects, development, etc. and suspicions about the vaccines because the government seems to be forcing individuals to take the vaccines whether they have a valid reason for putting off the vaccine or not. Blockchain can be use in disparate vaccine administration and to promote cybersecurity of data and other private information in a vaccine chain. Recommendations for vaccination in pregnant women and breastfeeding are also discussed. Other significant issues include the duration of vaccine protection, to get a booster or not, blending vaccines, etc.

Keywords: COVID19, SARSCoV2, Vaccines, Vaccine hesitancy, Herd immunity, Variants

Copyright : (C) 2021 The Authors. Published by Medical Editor and Educational Research Publishers Ltd. This is an open access article under the CC BY-NC-ND license (https://creativecommons.org/licenses/by-nc$\mathrm{nd} / 4.0 /)$. 


\section{1 | INTRODUCTION}

I November 2020, the US Food and Drug Administration (FDA) gave Emergency Use Authorization (EUA), to two vaccines - BNT162b2 (Pfiizer-BioNTech and mRNA-1273 (Moderna) for the SARS-CoV-2 virus which causes COVID-19. A month later, in December 2020, the European Medicines Agency approved several SARS-CoV2 vaccines. The vaccines were developed and approved in a record time (i.e., less than a year), based on blinded, random, and controlled trials. While each vaccine provides a different degree of immunity by encoding the spike protein antigen of SAR$\mathrm{CoV}-2$, the vaccines were developed using different manufacturing techniques. For example, PfizerBioNTech and Moderna are mRNA vaccines use a new technology which encapsulates the SARS-CoV2 spike protein in lipid nanoparticles. On the other hand, vaccines Ad26.COV2.S (Johnson \& Johnson/Janssen) and ChAdOx1 nCov-19 (AstraZeneca), use a much older vaccine technology using a vector. For example, the Johnson \& Johnson/Janssen vaccine uses a recombinant adenovirus type $26 \mathrm{vec}-$ tor to encode the SARS-CoV-2 spike glycoprotein and AstraZeneca uses a recombinant chimpanzee adenoviral vector to encode the spike glycoprotein. Because these COVID-19 vaccines were developed in a record amount of time, scientists and medical professionals may learn of new or rare side effects after the vaccine has entered the general population for administration. To keep track of the number, severity, age, and type of side effect, and whether the side effect(s) led to death, the US developed the VAERS website. For example, the AstraZeneca vaccine may result in the development of a rare immune thrombotic thrombocytopenia mediated by plateletactivating antibodies against PF4, which clinically mimics autoimmune heparin-induced thrombocytopenia (1). A safety concern temporally related to the administration of the AstraZeneca vaccine involving an unusual clinical constellation of abnormal clotting, should be discussed, especially cerebral venous thrombosis, and thrombocytopenia that has led to death in some cases (2).

In the US, although medical providers had just started to treat the first victims of COVID-19, US
President Donald J. Trump began research into developing and testing vaccines when on January 10 , 2020, researchers in China shared the genetic code of the SARS-CoV-2 ribonucleic acid (RNA) sequence. This code was helpful for genetic researchers to start developing and testing various vaccines using both newer and older vaccine technologies. Two Chinese companies, Sinopharm and Sinovac had trials underway on three vaccines that contained intact and inactivated coronavirus, harvested from live cell cultures, and chemically treated so that it cannot reproduce inside a person. China has a large manufacturing capacity for producing vaccines using an inactivated virus. To achieve herd immunity, researchers approximate for at least $55 \%-82 \%$ of the population to have either acquired or natural immunity to SARSCoV-2. Therefore, public acceptance of COVID-19 vaccines is imperative to achieving herd immunity, which allows the population to function at a $95 \%$ "normal" activity level. However, racial disparities do exist in black and brown communities. The attitude of black and brown communities also leans towards hesitancy and suspicion of the vaccination. Community outreach in these communities, an educational blitz of the benefits of vaccination versus the severity of COVID-19 and its long-term effects can help dispel much of the anxiety among minority communities. Countering public misinformation will also help in the advocacy of vaccination. This can include countering misinformation put forth by talk shows, the media, social media sites, and within the community. Widespread education about the vaccines needs to include communities of all types (34).

For healthcare workers, health maintenance and vaccination is a concern so that society continues to have access to quality healthcare with adequate levels of staffing. Although vaccination is important in health-

Supplementary information The online version of this article (DOIhttps://doi.org/10.52845/JMRHS/20 21-4-12-2) contains supplementary material, which is available to authorized users.

Corresponding Author: Cheryl Ann Alexander Institute for IT innovation and Smart Health, Mississippi, USA 
care workers, there are also those with prior exposure to COVID-19 who now have natural immunity. Current research thus far, in particular the leading vaccination research in Israel indicates that vaccination of those with natural immunity may cause harmful side effects leading to damage, illness, disability, or death. But pandemic preparedness depends upon those individuals able to staff critical care units and emergency departments, as well as the other functioning units of a modern healthcare facility. Unfortunately, with the high rate of transmission among healthcare workers at all levels, a low proportion of COVID-19 vaccine acceptance, and an aversion to vaccine mandates, evidence-based planning on vaccination strategies for healthcare workers should have been made in advance of the implementation of the vaccines (5).

The purpose of this comprehensive review paper is to introduce and discuss a few important issues surrounding the COVID-19 vaccines. The subsequent sections of the paper are arranged as follows: the second section introduces the types of COVID19 vaccines; the third section presents how major SARS-CoV-2 variants may affect vaccine efficacy; the fourth section introduces vaccine acceptance and hesitancy; the fifth section deals with the impacts of social media and other sources of COVID-19 misinformation on the public opinion of vaccination; the sixth section introduces the logistics of vaccine administration, disparate populations and their access to the vaccine, and cybersecurity needs based on blockchain; the seventh section is a discussion; and the eighth section is the conclusion.

\section{2 | TYPES OF COVID-19 VACCINES}

There are several types of COVID-19 vaccine technologies. Each vaccine type differs in the method it uses to deliver the Spike glycoprotein antigen to establish acquired immunity. Each type of vaccine and the technology used to deliver it to the host individual carries its own set of potential side effects and precautions. The US uses the VAERS website to establish a database to monitor side effects and the reactions of vaccinated individuals. While all vaccinations are considered medications and therefore, have the potential for varying degrees of side effects, some types of vaccines account for most of the adverse events associated with vaccination. Types of COVID-19 vaccines include genetic vaccines-Deoxyribonucleic acid (DNA) and messenger Ribonucleic acid (RNA) vaccines, viral vector vaccines, viral subunit vaccines, live attenuated vaccines, and inactivated virus vaccines. The risks, immune response, and ease of production of various types of vaccines are listed in Table 1 (6). Table 2 (7) compares four vaccines that have been recommended by the World Health Organization (WHO). Some vaccines have been used in multiple countries, tested in countries outside the country of development, and donated by countries with a strong economy to countries with a weaker economy. Pfizer/BioNTech has announced the efficacy of $95 \%$ with its vaccine; Moderna has announced its efficacy at $94.5 \%$; and AstraZeneca has announced a lower efficacy of $70 \%$. The Chinese company Sinopharm announced the efficacy of its vaccine at 79\% (810). Table 3 (11-13) lists the basic reproduction number, the vaccine efficacy, and the herd immunity threshold of several diseases.

Table 1: Risks, immune response, and ease of production of vaccines

\begin{tabular}{|c|c|c|c|}
\hline Type of vaccine & Ease of production & Immune response & Risks \\
\hline RNA vaccine & Easy & Strong & Safe \\
\hline DNA vaccine & $\begin{array}{l}\text { Require special } \\
\text { facility }\end{array}$ & Medium & $\begin{array}{l}\text { Risk of integration } \\
\text { muttation }\end{array}$ \\
\hline $\begin{array}{l}\text { Live attenluated } \\
\text { vaccine }\end{array}$ & Easy & $\begin{array}{l}\text { Robust } \\
\text { Response }\end{array}$ & Risk of infection \\
\hline Viral vector vaccine & Easy & Strong & $\begin{array}{l}\text { Risk of integration } \\
\text { mutation }\end{array}$ \\
\hline Inactivated vaccine & $\begin{array}{l}\text { Require special } \\
\text { facility }\end{array}$ & Strong & Safe \\
\hline Subunit vaccine & Easy & Strong & Safe \\
\hline
\end{tabular}

Table2 : Comparison of four COVID-19 vaccines 
MEERP LTD

\begin{tabular}{|c|c|c|c|c|}
\hline Vaccine & Moderna & Pfizer/BioNTech & Janssen & AstraZeneca \\
\hline Authorization & US, UK, Europe & $\begin{array}{l}\text { US, UK, } \\
\text { Europe, } \\
\text { Canada, } \\
\text { Australia }\end{array}$ & $\begin{array}{l}\text { US, Europe } \\
\text { (Use paused } \\
\text { in some } \\
\text { countries) }\end{array}$ & $\begin{array}{l}\text { UK, Europe, } \\
\text { Australia } \\
\text { (Use paused in } \\
\text { some countries) }\end{array}$ \\
\hline $\begin{array}{c}\text { Authorized } \\
\text { dose(s) }\end{array}$ & $\begin{array}{c}\text { Two doses, } \\
\text { second dose at } \\
\text { least } 28 \text { days after } \\
\text { first dose, } \\
\text { booster after } 9 \\
\text { months }\end{array}$ & $\begin{array}{l}\text { Two doses, } \\
\text { second dose at } \\
\text { least } 21 \text { days } \\
\text { after first dose, } \\
\text { booster after } 6 \\
\text { months }\end{array}$ & Single dose & $\begin{array}{l}\text { Two doses, } \\
\text { second dose } 4 \text { - } \\
12 \text { weeks after } \\
\text { first dose, } \\
\text { booster }\end{array}$ \\
\hline $\begin{array}{l}\text { Overall } \\
\text { efficacy }\end{array}$ & $94 \%$ & $95 \%$ & $66 \%$ & $\begin{array}{l}55 \% \text { to } 80 \% \\
\text { (Depending on } \\
\text { the dose } \\
\text { interval) }\end{array}$ \\
\hline $\begin{array}{l}\text { Indication } \\
\text { (Active } \\
\text { immunization } \\
\text { of individuals' } \\
\text { ages) }\end{array}$ & $\geq 18$ years & $\begin{array}{c}\geq 16 \text { years } \\
5-11 \text {-year-olds }\end{array}$ & $\geq 18$ years & $\geq 18$ years \\
\hline $\begin{array}{c}\text { Common } \\
\text { adverse events }\end{array}$ & $\begin{array}{l}\text { Headache, chills, } \\
\text { fever, nausea, } \\
\text { fatigue, rash, } \\
\text { vomiting, } \\
\text { diarrhea, } \\
\text { myalgia, } \\
\text { arthralgia, } \\
\text { axillary, injection- } \\
\text { site reactions, } \\
\text { lymphadenopathy } \\
\text { (On same side as } \\
\text { injection site) }\end{array}$ & $\begin{array}{c}\text { Headache, } \\
\text { chills, } \\
\text { fever, nausea, } \\
\text { fatigue, myalgia, } \\
\text { arthralgia, } \\
\text { injection-site } \\
\text { reactions }\end{array}$ & $\begin{array}{l}\text { Headache, } \\
\text { hills, fever, } \\
\text { cough, nausea, } \\
\text { fatigue, } \\
\text { myalgia, } \\
\text { arthralgia, } \\
\text { injection-site } \\
\text { reactions }\end{array}$ & $\begin{array}{l}\text { Headache, hills, } \\
\text { fever, nausea, } \\
\text { fatigue, } \\
\text { vomiting, } \\
\text { diarrhea, } \\
\text { myalgia, } \\
\text { malaise, } \\
\text { arthralgia, } \\
\text { influenza-like } \\
\text { illness, } \\
\text { injection-site } \\
\text { reactions }\end{array}$ \\
\hline $\begin{array}{l}\text { Serious adverse } \\
\text { events }\end{array}$ & $\begin{array}{l}\text { Stroke, significant } \\
\text { micro clotting, } \\
\text { fatal } \\
\text { side effects, } \\
\text { myocarditis in } \\
\text { younger males }\end{array}$ & $\begin{array}{c}\text { Stroke, } \\
\text { significant micro } \\
\text { clotting, fatal } \\
\text { side effects, } \\
\text { myocarditis in } \\
\text { younger males }\end{array}$ & $\begin{array}{l}\text { Significant } \\
\text { fatal side } \\
\text { effects, } \\
\text { myocarditis in } \\
\text { younger males }\end{array}$ & $\begin{array}{c}\text { Stroke, } \\
\text { significant } \\
\text { micro clotting, } \\
\text { fatal side effects }\end{array}$ \\
\hline
\end{tabular}

Table3: Metrics for SARS-CoV-2 vaccines and previously approved vaccines of other diseases

\begin{tabular}{|c|c|c|c|}
\hline Diseases & $\begin{array}{c}\text { Basic reproduction } \\
\text { number }\left(\mathrm{R}_{0}\right)\end{array}$ & $\begin{array}{c}\text { Vaccine efficacy } \\
(\%)\end{array}$ & $\begin{array}{c}\text { Herd immunity } \\
\text { threshold }(\%)\end{array}$ \\
\hline Measles & $12-18$ & 94 & $55-94$ \\
\hline Rubella & $6-7$ & $94-95$ & $83-85$ \\
\hline Spanish flu 1918 & $2-3$ & NA & $50-67$ \\
\hline Ebola & $1.5-2.5$ & $95-100$ & $33-60$ \\
\hline SARS-CoV-2 & $2.5-5.8$ & $60-95$ & $60-83$ \\
\hline
\end{tabular}

\section{3 | MAJOR SARS-COV-2 VARIANTS}

With the recent surge in COVID-19 cases among both the vaccinated and unvaccinated, new concerns about a reduction in neutralizing antibodies and the possible resistance of the COVID-19 vaccines to certain SARS-CoV-2 variants surged to the forefront of medical research. Studies suggest that the Pfizer/BioNTech vaccine should be effective for the B.1.1.7 variant - also known as the Delta variantan observation consistent with previous reports that showed preserved neutralizing antibody titers (14). The B.1.1.7 (N501Y.V1) lineage was first detected in the United Kingdom and rapidly spread to other countries, including the US and includes the N501Y mutation of the spike protein, which has demonstrated 53\% affinity for the ACE2 receptor, resulting in an increase in transmissibility. Another variant, B.1.351 (also known as N501Y.V2 or the South African variant) first evolved in South Africa. The AstraZeneca vaccine was developed at University of Oxford, UK. A two-dose regimen of this vaccine demonstrated a failure to protect against mild-tomoderate COVID-19 due to the B.1.351 variant (15).

South Africa suspended the use of AstraZeneca's COVID-19 vaccine after it failed to stop COVID-19 caused by SARS-CoV-2 variants. About 2,000 subjects participated in the South African AstraZeneca vaccine trial. Efficacy in mild and moderate COVID19 disease was less than $25 \%$; too low to meet minimal international standards for emergency use. However, scientists postulate that the vaccine might still prevent severe disease and death which is arguably the most important job for any COVID-19 vaccine. Both Johnson \& Johnson (J\&J) and Novavax vaccines also produced a weak response to the South African variant, which caused most of the infections in South Africa. The J\&J and Novavax vaccines provided a lower efficacy in South African subjects against the South African variant.: the J\&J vaccine showed a $57 \%$ efficacy against mild disease and the Novavax vaccine had a confirmed efficacy of just $49 \%$ against the South African variant, which is the lowest of any other country they were tested (16).

\section{4 | VACCINE ACCEPTANCE AND HESITANCY}




\section{Vaccine Acceptance}

Two cross-sectional surveys were completed online during the first wave (February 2020) and third wave (from August to September 2020) of the epidemic in Hong Kong. The reduced willingness for accepting COVID-19 vaccines was probably related to the increase of concerns about the vaccine's safety and the growing compliance of personal protection behaviors. The rapid vaccine development with possible high safety risks may decrease the public's trust and lower uptake rates (17).

The acceptance of the COVID-19 vaccines may rely on features of the vaccines (e.g., cost, timeliness of vaccination, side effects, risk to reproductive health, etc.), the national vaccination strategy (e.g., education about the vaccine and vaccine production techniques, answers to common questions by healthcare workers, first responders, frontline workers, etc.), and various other factors in the working-age population in France. Anti-COVID-19 vaccination behaviors were greatly related to specific traits among participants; for example, lower educational levels, female/gender, no report of chronic conditions, ages with an inverted U-shaped relationship, the perception of a lower severity of COVID-19 if infected, and poor compliance with recommended vaccinations in the past. COVID-19 vaccine hesitancy was reduced with a higher vaccine efficacy and a lower risk of serious side-effects and was much higher if vaccination was accessible only in mass vaccination centers rather than a general practitioner practice or local pharmacy. A more successful implementation of a COVID-19 vaccine strategy in France with the vaccines made in the EU and with a communication strategy emphasizing the collective benefits of herd immunity in the working-age population (18).

On December 25, 2020, scientists conducted a literature survey study on COVID-19 vaccine acceptance rates in 33 countries. The highest acceptance rates $(>90 \%)$ for vaccines among the public are shown in Table 4 (19). The lowest COVID-19 vaccine acceptance rates $(<60 \%)$ are shown in Table 5 (19). There were changes in the vaccine acceptance rates over time in countries. Influencing factors of a lower acceptance of COVID-19 vaccines that were given by participants of an investigation are listed in Table $6(20)$ :
Table 4: Countries with the highest vaccine acceptance rates

\begin{tabular}{|c|c|c|c|c|}
\hline Countries & Ecuador & Malaysia & Indonesia & China \\
\hline Acceptance rates (\%) & 97.0 & 94.3 & 93.3 & 91.3 \\
\hline
\end{tabular}

Table 5: Countries with the lowest vaccine acceptance rates

\begin{tabular}{|c|c|c|c|c|c|c|c|}
\hline Countries & Kulwait & Jordan & Italy & Russia & Poland & US & France \\
\hline Acceptance rates (\%) & 23.6 & 28.4 & 53.7 & 54.9 & 56.3 & 56.9 & 58.9 \\
\hline
\end{tabular}

Table 6: Influencing factors of a lower acceptance of COVID-19 vaccines

\begin{tabular}{|c|c|}
\hline Influencing factors & Description \\
\hline Gender & Women had a lower acceptance. \\
\hline Age & A young age was related to a lower acceptance. \\
\hline Ethnicity & Black/African people had a lower vaccination rate. \\
\hline Income & Participants with a lower income had a lower acceptance. \\
\hline Education & Individuals with low education had a lower vaccination rate. \\
\hline Working status & Unemployed people had a lower vaccination rate. \\
\hline Religiosity & Religiosity was negatively associated with a lower acceptance. \\
\hline $\begin{array}{l}\text { Concerns about } \\
\text { COVID-19 }\end{array}$ & $\begin{array}{l}\text { People with strong concerns about being infected probably did not } \\
\text { refuse vaccination. }\end{array}$ \\
\hline Personal belief & $\begin{array}{l}\text { Individuals with personal belief against vaccination had a lower } \\
\text { vaccination rate; people with past vaccination (especially influenza) } \\
\text { had a higher vaccination rate. }\end{array}$ \\
\hline
\end{tabular}

Healthcare workers are at the frontline of the COVID-19 infection and recognized as a priority target group for COVID-19 vaccination. Nurses or nursing assistants were less prone to accept COVID-19 vaccines than physicians. Older age, males, fears about COVID-19, individual perceived risks and flu vaccination during previous seasons were related to hypothetical COVID-19 vaccination acceptance. Vaccine hesitancy was associated with a decrease in vaccine acceptance (21). 


\section{Vaccine Hesitancy}

According to the definition of World Health Organization Strategic Advisory Group of Experts (SAGE), vaccine hesitancy is the delay in acceptance or refusal of vaccination despite the availability of vaccination services (22-23). Vaccine hesitancy has become a global challenge threatening herd immunity and making evaluation of trends a critical tool in debunking myths about the COVID-19 vaccines to achieve vaccination levels necessary for global herd immunity. Estimates to reach herd immunity range between $60 \%$ and $95 \%$. Therefore, developing a tool to measure and evaluate strategies to increase the uptake of the vaccine among the most vulnerable populations becomes critical not only to reach herd immunity but to save lives. Existing validated evaluation tools have only measured vaccine hesitancy in the past by examining confidence in the vaccine itself and the medical system which delivers it. Consequently, to address the current state of vaccine hesitancy, scientists developed the 5C psychological antecedents of vaccination which includes confidence (i.e., trust in vaccine safety, necessity, and effectiveness as well as the system that delivers it), complacency (i.e., perceived the disease as a low risk), constraints (i.e., perceived low vaccine availability, accessibility, and affordability), calculation (i.e., engagement in in information searching), and collective responsibility (i.e., willingness to take vaccines for safeguarding other people, the establishment of herd immunity). The 5C constructs address not only physical barriers, but psychological barriers as well, which are by far the hardest areas to assess for vaccine hesitancy but are crucial to a vaccination campaign and were a key component in forecasting vaccine readiness among study participants, therefore, the 5C constructs should have been a crucial building block for establishing a vaccine readiness campaign (24). Healthcare workers are not exempt from vaccine hesitancy despite working with the SARS-CoV-2 virus daily and exposing themselves to the highest level of risk from COVID-19 infection to themselves and their families and friends. Nurses tend to be more emotional and concerned about the vaccines from a reproductive standpoint and from the viewpoint that many healthcare workers were exposed early in the pandemic and many now have natural immunity and feel that the vaccine exposes them to unnecessary risk if taken. Using a conveniencebased, depending upon chain-referral sampling, a study of 1019 study participants including all areas of healthcare workers was conducted to determine vaccine hesitancy and corresponding 5C. Using the 5C subscales, the overall rate of vaccine acceptance was $83 \%$, with the highest rate seen in dentists. However, the lowest rate for vaccine acceptance was seen in nurses. A higher level of vaccine hesitancy was seen in females and lower education levels. Nurses are a creditable and trustworthy source of the information about vaccines and can help build public confidence in vaccines. Thus, it is imperative that officials take every precaution to keep healthcare workers healthy and free of infection. It is crucial that a positive attitude toward vaccination is cultivated, and an atmosphere of acceptance and respect aimed at listening to opinions and experiences of not only healthcare workers, but also first responders and frontline workers. The studies show that more emphasis should have been placed widespread education and on psychological barriers against vaccinations when initiating nationwide programs of vaccines (24).

Numerous reasons have been cited by individuals for refusing the vaccines. However, the primary reasons for refusal tend to be concern for safety of the vaccines, doubts whether the vaccines are efficient given the high case numbers among the vaccinated. Other individuals have a general lack of trust for the vaccines or simply do not vaccinate in general. Additionally, some think that the vaccine may be dangerous because it was developed in nine months, when on average, it takes 3-5 years to develop a vaccine. There is also the thought that COVID-19 is harmless and will 
not make you ill and there are those who were sick with COVID-19 who have natural immunity (20). Many of these reasons, however, are fostered by the media's portrayal of COVID-19 and the vaccine, and other influencers such as social media and politicians, celebrities and others who have societal influence who have helped to create much of the social inequalities related to vaccine hesitancy. The majority of individuals who have not gotten vaccinated include younger minority women with little education or who belong to a lower income level. For healthcare professionals to increase widespread vaccination, it is important to address these factors and attempt to bridge the ethnic or minority inequalities (25). Researchers conducted an online COVID-19 survey about vaccine hesitancy with 12,035 participants completing the survey. Table 7 (26) shows the reasons of vaccine hesitancy given by the participants and the percentage of each reason:

Table 7: Reasons for COVID-19 vaccine hesitancy

\begin{tabular}{|l|c|}
\hline \multicolumn{1}{|c|}{ Hesitancy reasons } & Percentages (\%) \\
\hline Worries about unknown future effects of the vaccines & 42.70 \\
\hline Other & 12.20 \\
\hline Worrying about side-effects & 11.40 \\
\hline Vaccines are limited and other people need them more than me & 7.70 \\
\hline Not trusting vaccines & 7.60 \\
\hline The possibility of becoming critically ill from CoVID-19 is low for me & 6.20 \\
\hline I have a minimal chance of catching COVID-19 & 4.50 \\
\hline The effects of CoVID-19 have been considerably exaggerated & 3.20 \\
\hline The vaccines are ineffective at preventing me from catching COVID-19 & 1.5 \\
\hline Not believing that vaccines are free (no need to pay for them) & 1.4 \\
\hline Unsafe for me because I have a condition & 1.0 \\
\hline Herd immunity will prevent the unvaccinated from catching COVID-19 & 0.4 \\
\hline
\end{tabular}

\section{I IMPACT OF VACCINE MISINFORM ATION FROM SOCIAL MEDIA AND OTHER SOURCES}

Twitter is one of the most well-known media platforms because users can easily post information or opinions on any topic. Misinformation about vaccination has become a key problem among Twitter users. Researchers collected and annotated a COVID-19 vaccination dataset. Public opinions associated with the COVID-19 vaccination process was analyzed based on messages posted on Twitter. The performance for stance (e.g., in favor, against or neutral) detection based on several machine learning algorithms (i.e., classical machine learning and deep learning algorithms) was compared. The classifier with the best performance for COVID-19 vaccination stance detection can be determined (27).

A trial was conducted in the US and the UK to quantify how exposure to online misinformation surrounding COVID-19 vaccines affects the intent to vaccinate. Data revealed that as of September 2020, fewer participants would 'definitely' take a vaccine than is required for herd immunity and that misinformation could push these levels even further away from herd immunity targets as misinformation lowers people's intent to accept a COVID-19 vaccine. A platform was provided to help understand and test how more successful public health communication strategies could be designed and on whom these strategies would have the most positive impact on thwarting COVID-19 vaccine misinformation (28).

Table 8 (29) shows the degree to which groups displayed COVID-19 vaccine acceptance, hesitancy, and resis-tance exists in a group of UK respondents from nine separate sources. A standard Likert scale with a $1-4$ rating - $(1=$ none, $2=$ a little, $3=$ some, $4=$ a lot) —was used to measure 'Sources of COVID-19 Information'.

\section{Table 8: Sources of COVID-19 information influencing vaccine resistance, hesitancy, and acceptance in a UK sample.}




\begin{tabular}{|c|c|c|c|}
\hline Sources & Resistant & Hesitant & Accepting \\
\hline Newspaper & 1.94 & 2.13 & 2.26 \\
\hline Television & 2.86 & 3.15 & 3.40 \\
\hline Radio & 2.19 & 2.30 & 2.34 \\
\hline Internet & 2.77 & 2.74 & 2.84 \\
\hline Social media & 2.36 & 2.24 & 2.15 \\
\hline Your doctor & 1.43 & 1.52 & 1.43 \\
\hline Health professional & 1.88 & 1.80 & 1.76 \\
\hline Government agencies & 2.28 & 2.37 & 2.50 \\
\hline Family or friends & 2.35 & 2.27 & 2.28 \\
\hline
\end{tabular}

\section{6 | BLOCKCHAIN-BASED IMPROVEMENT OF DISPARITIES AND INCREASED CYBERSECURITY}

The COVID-19 pandemic exposed many inequalities and disparities in minority communities, particularly in geographical areas with lower incomes and limited or no education. Although US President Donald J. Trump secured enough vaccine to vaccinate everyone qualified to receive the vaccine in the United States when the vaccines were being developed as part of Operation Warp Speed, an incredible step forward and an amazing medical supply solution for a potential medical supply chain conundrum. US President Trump had ordered enough of the vaccine while it was being tested to vaccinate everyone in the US using military logistics. But, after January 20, 2021, the over $1,000,000$ vaccine doses per day that were being given prior to that, decreased, and continued to fall for the next 11 months. Furthermore, because the initial global supply of the COVID-19 vaccines was limited, so questions on how to prioritize available doses were raised. There are two primary approaches to vaccine prioritization: 1) directly vaccinate people who exhibit the highest risk for severe outcomes, 2) protect the vulnerable by vaccinating individuals who do the most transmitting. A modelinformed approach was used to quantify the impact of COVID-19 vaccine prioritization strategies on cumulative incidence, mortality, and years of life lost. After distribution, pairing serological testing with vaccination in the hardest-hit populations is one possible equitable way to extend the benefits of vaccination in settings where vaccination may otherwise not be deemed cost effective. Vaccine prioritization is not only a question of science but a question of ethics as well (30).

A vaccine allocation strategy based on time-varying linear optimization was proposed that incorporates epidemiological factors, such as susceptible count, population density, and infected ratio as well as transportation costs to disseminate vaccines among regions. It was suggested that incorporating the vulnerability score of regions to the epidemic spread into vaccine allocation should improve recommendations and aid policy making (31). A blockchainbased system was introduced for the transparent tracing of COVID-19 vaccine registration, storage and delivery, and self-reporting of significant side effects. The following are benefits of a cybersecure blockchain-based system for increasing vaccine distribution to disparate areas (32):

- data transparency, immutability, and correctness of beneficiary registration for vaccination to avoid identity thefts and impersonations

- decentralized smart contracts-based solution to monitoring proper vaccine transportation conditions in a cold chain and real-time awareness of COVID19 vaccine delivery and storage conditions to all concerned

- smart contracts-based solution to vaccine administration and tamper-proof self-reporting of side effects, person recognition, and vaccine association

During the first phase of COVID-19, the WHO did not suggest using "immunity passports" since there was no evidence of a permanent immunity once a person was infected and recovered from COVID-19. 
The WHO has suggested using e-vaccination certificates (33). And although blockchain shows promise, there are still significant problems to be solved in implementation. One of these problems is the throughput of blockchain platforms, which may be too low for some applications and depends on the number of nodes participating in the protocol and the number of transactions they generate. A related matter concerns transactions acceptance latency, which is dependent on the time necessary to validate a block. New consensus algorithms have been developed to fix these problems. But permissioned blockchains have a higher level of efficiency, making it more cybersecure. The biggest challenge, however, is the trade-off between privacy and data auditability; so, sensitive data must comply with

privacy laws and regulations. All these issues are cybersecurity-related and the nature of blockchain and its promising cybersecure applications tend to make it more attractive in highly cybersecure areas where identity and other identifying data are concerned. Encouraging cryptographic techniques, such as zero-knowledge proofs, can be used to keep the advantages of blockchain and ensure privacy of the data and the applications related to cybersecurity (33).

\section{7 | DISCUSSION}

COVID-19 mRNA vaccines generate a strong humoral immunity in pregnant and lactating women, with immunogenicity and reactogenicity like that detected in non-pregnant women (34). Preliminary findings did not show obvious safety signals among pregnant women who received mRNA COVID-19 vaccines. The percentages of adverse pregnancy and neonatal outcomes (e.g., preterm birth, congenital anomalies, fetal loss, small size for gestational age, and neonatal death) among participants with birth from the v-safe pregnancy registry seem to be like published incidences in pregnant women populations studied before the COVID-19 pandemic. In addition, emerging evidence has shown a transplacental transfer of SARS-CoV-2 antibodies after maternal COVID-19 vaccination during the third trimester, which indicates that maternal vaccination possibly provides some level of protection to the neonate. Injection-site pain was reported more frequently among pregnant women than non-pregnant women, whereas chills, fever, myalgia, and headache were reported less frequently (35).

Government and health authorities should build a transparent, reasonable, and robust immunization process for COVID-19 vaccines with contexttailored vaccine communication that addresses public concerns (22). The strongest predictor of having high-level intention to take a COVID-19 vaccine was trusting vaccines to be safe. Informing the public about the safety of a forthcoming vaccine is very important (36). Much remains unknown or needs to be addressed regarding the use of COVID-19 vaccines (37):

- What is their duration of protection, and will booster doses be needed?

- Will they protect against asymptomatic infection and carrier states, and thereby prevent transmission?

- Can they be co-administered with other vaccines?

- Will they be efficacious and safe to use during pregnancy and breastfeeding?

\section{8 | CONCLUSION}

The resistance of SARS-CoV-2 variants to COVID19 vaccines and neutralizing antibodies are a significant concern. When vaccine hesitancy overflows into healthcare workers and triggers a resulting shortage of workers due to an implementation of vaccine mandates, vaccine passports, or other required documentation of vaccination, the problem of vaccine hesitancy has far-reaching effects, especially in vulnerable populations who may need to be hospitalized and there is a lack of nursing staff, physicians, technicians, etc. A widespread global education program of vaccine education, not vaccine mandates, is a far better application because it can address the public's concerns and increase the numbers of vaccinated individuals because the benefits and contraindications of the COVID-19 vaccines have been applied to a public forum. Vaccine misinformation must not be 
tolerated as well as a lack of education in vaccinated individuals. With the increase in mutated variants, and the global infectivity rate still far below herd immunity, interventions targeting those populations with hesitancy and a lack of education about the vaccines, whether from negative social media influences or from untruthful media portrayal of case numbers, side effects among those vaccinated, and deaths, etc. Influencing factors of lower COVID-19 vaccine acceptance lie in: gender, age, ethnicity, income, education, working status, religiosity, concern about COVID-19, and personal belief. Vaccination hesitancy is decreased with higher vaccine efficacy and lower risk of serious sideeffects. Social media has substantial impacts on public opinions of vaccination. Government and health agencies should build a transparent, reasonable, and robust immunization process for COVID-19 vaccines. Blockchain can be employed for the transparent tracing of COVID-19 vaccine registration, storage and delivery, and side effects self-reporting, however, there needs to be much attention for sensitive data and privacy. Future research lies in gathering more information about the reasons for vaccine hesitancy and methods to alleviate the public's fears about the COVID-19 vaccines.

\section{9 | REFERENCES}

1. Greinacher A, Thiele T, Warkentin TE, Weisser K, Kyrle PA, Eichinger S. Thrombotic thrombocytopenia after ChAdOx1 nCov-19 vaccination. New England Journal of Medicine. 2021 Jun 3;384(22):20922101.

2. Scully M, Singh D, Lown R, Poles A, Solomon T, Levi M, Goldblatt D, Kotoucek P, Thomas W, Lester W. Pathologic antibodies to platelet factor 4 after ChAdOx 1 nCoV-19 vaccination. New England Journal of Medicine. 2021 Jun 10;384(23):2202-2211.

3. Goldschmidt K. COVID-19 vaccines for children: The essential role of the pediatric nurse. Journal of Pediatric Nursing. 2021 Mar 1.
4. Gibbs WW. This Is How to Vaccinate the World: We can manufacture and distribute enough doses to protect humanity from COVID-19. IEEE Spectrum. 2020 Dec 30;58(1):32-37.

5. Wang K, Wong EL, Ho KF, Cheung AW, Chan EY, Yeoh EK, Wong SY. Intention of nurses to accept coronavirus disease 2019 vaccination and change of intention to accept seasonal influenza vaccination during the coronavirus disease 2019 pandemic: A cross-sectional survey. Vaccine. 2020 Oct 21;38(45):7049-56. Available from: https://doi.org/ 10.1016/j.vaccine.2020.09.021.

6. GURAJALA S. A Sneak Peek into COVID-19 Vaccines-Present Status. Journal of Clinical \& Diagnostic Research. 2021 Mar 1;15(3).

7. Beeching NJ, Fletcher TE, Fowler R. BMJ best practice-coronavirus disease 2019 (COVID-19), White Paper, Apr 22, 2021.

8. Kim JH, Marks F, Clemens JD. Looking beyond COVID-19 vaccine phase 3 trials. Nature medicine. $2021 \mathrm{Feb} ; 27(2): 205-11$. Available from: https://doi. org/10.1038/s41591-021-01230-y.

9. Polack FP, Thomas SJ, Kitchin N, Absalon J, Gurtman A, Lockhart S, Perez JL, Marc GP, Moreira ED, Zerbini C, Bailey R. Safety and efficacy of the BNT162b2 mRNA Covid-19 vaccine. New England Journal of Medicine. 2020 Dec 10.

10. Voysey M, Clemens SA, Madhi SA, Weckx LY, Folegatti PM, Aley PK, Angus B, Baillie VL, Barnabas SL, Bhorat QE, Bibi S. Safety and efficacy of the ChAdOx1 nCoV-19 vaccine (AZD1222) against SARS-CoV-2: an interim analysis of four randomised controlled trials in Brazil, South Africa, and the UK. The Lancet. 2021 Jan 9;397(10269):99111.

11. Henao-Restrepo AM, Camacho A, Longini IM, Watson $\mathrm{CH}$, Edmunds WJ, Egger M, Carroll MW, Dean NE, Diatta I, Doumbia M, Draguez B. Efficacy and effectiveness of an rVSV-vectored vaccine in preventing Ebola virus disease: final results from the Guinea ring vaccination, open-label, clusterrandomised trial (Ebola Ça Suffit!). The Lancet. 2017 Feb 4;389(10068):505-518. 
12. Petersen E, Koopmans M, Go U, Hamer DH, Petrosillo N, Castelli F, Storgaard M, Al Khalili S, Simonsen L. Comparing SARS-CoV-2 with SARS$\mathrm{CoV}$ and influenza pandemics. The Lancet infectious diseases. $2020 \mathrm{Jul} 3$.

13. Gomes MG, Corder RM, King JG, Langwig KE, Souto-Maior C, Carneiro J, Gonçalves G, PenhaGonçalves C, Ferreira MU, Aguas R. Individual variation in susceptibility or exposure to SARS-CoV-2 lowers the herd immunity threshold. MedRxiv. 2020 Jan 1.

14. Dagan N, Barda N, Kepten E, Miron O, Perchik S, Katz MA, Hernán MA, Lipsitch M, Reis B, Balicer RD. BNT162b2 mRNA Covid-19 vaccine in a nationwide mass vaccination setting. New England Journal of Medicine. 2021 Apr 15;384(15):14121423.

15. Madhi SA, Baillie V, Cutland CL, Voysey M, Koen AL, Fairlie L, Padayachee SD, Dheda K, Barnabas SL, Bhorat QE, Briner C. Efficacy of the

ChAdOx1 nCoV-19 Covid-19 vaccine against the B. 1.351 variant. New England Journal of Medicine. 2021 May 20;384(20):1885-1898.

16. Cohen J. South Africa suspends use of AstraZeneca's COVID-19 vaccine after it fails to clearly stop virus variant. Science. 2021;10.

17. Wang K, Wong EL, Ho KF, Cheung AW, Yau PS, Dong D, Wong SY, Yeoh EK. Change of willingness to accept COVID-19 vaccine and reasons of vaccine hesitancy of working people at different waves of local epidemic in Hong Kong, China: Repeated cross-sectional surveys. Vaccines. 2021 Jan;9(1):62. Available from: https://doi.org/10.3390 /vaccines9010062.

18. Schwarzinger M, Watson V, Arwidson P, Alla F, Luchini S. COVID-19 vaccine hesitancy in a representative working-age population in France: a survey experiment based on vaccine characteristics. The Lancet Public Health. 2021 Apr 1;6(4):e210221. Available from: https://doi.org/10.1016/ S24682667(21)00012-8.

19. Sallam M. COVID-19 vaccine hesitancy worldwide: a concise systematic review of vaccine acceptance rates. Vaccines. $2021 \mathrm{Feb} ; 9(2): 160$. Available from: https://doi.org/10.3390/vaccines9020160.
20. Troiano G, Nardi A. Vaccine hesitancy in the era of COVID-19. Public Health. 2021 Mar 4. Available from: https://doi.org/10.1016/j.puhe.2021.02.025.

21. Gagneux-Brunon A, Detoc M, Bruel S, Tardy B, Rozaire O, Frappe P, Botelho-Nevers E. Intention to get vaccinations against COVID-19 in French healthcare workers during the first pandemic wave: a cross-sectional survey. Journal of Hospital Infection. 2021 Feb 1;108:168-173. Available from: https://do i.org/10.1016/j.jhin.2020.11.020.

22. Wang Q, Xiu S, Zhao S, Wang J, Han Y, Dong S, Huang J, Cui T, Yang L, Shi N, Liu M. Vaccine Hesitancy: COVID-19 and Influenza Vaccine Willingness among Parents in Wuxi, China-A Cross-Sectional Study. Vaccines. 2021 Apr;9(4):342. Available from: https://doi.org/ 10.3390/vaccines 9040342 .

23. MacDonald NE. SAGE Working Group on Vaccine Hesitancy. Vaccine hesitancy: definition, scope and determinants. Vaccine. 2015 Aug 14;33(34):4161.

24. Kwok KO, Li KK, Wei WI, Tang A, Wong SY, Lee SS. Influenza vaccine uptake, COVID-19 vaccination intention and vaccine hesitancy among nurses: A survey. International journal of nursing studies. $2021 \mathrm{Feb}$ 1;114:103854. Available from:

https://doi.org/10.1016/j.ijnurstu.2020.103854.

25. Robinson E, Jones A, Lesser I, Daly M. International estimates of intended uptake and refusal of COVID-19 vaccines: A rapid systematic review and meta-analysis of large nationally representative samples. Vaccine. 2021 Feb 6. Available from:

https://doi.org/10.1016/j.vaccine.2021.02.005.

26. Robertson E, Reeve KS, Niedzwiedz CL, Moore J, Blake M, Green M, Katikireddi SV, Benzeval MJ. Predictors of COVID-19 vaccine hesitancy in the UK household longitudinal study. Brain, behavior, and immunity. 2021 May 1;94:41-50. Available from:

https://doi.org/10.1016/j.bbi.2021.03.008.

27. Cotfas LA, Delcea C, Roxin I, Ioanăş C, Gherai DS, Tajariol F. The Longest Month: Analyzing COVID-19 Vaccination Opinions Dynamics from Tweets in the Month following the First Vaccine Announcement. IEEE Access. 2021 Feb 16;9:3320323. 
28. Loomba S, de Figueiredo A, Piatek SJ, de Graaf $\mathrm{K}$, Larson HJ. Measuring the impact of COVID19 vaccine misinformation on vaccination intent in the UK and USA. Nature human behaviour. 2021 Mar;5(3):337-48. Available from: https://doi.org/10 .1038/s41562-021-01056-1.

29. Murphy J, Vallières F, Bentall RP, Shevlin M, McBride O, Hartman TK, McKay R, Bennett K, Mason L, Gibson-Miller J, Levita L. Psychological characteristics associated with COVID-19 vaccine hesitancy and resistance in Ireland and the United Kingdom. Nature communications. 2021 Jan 4;12(1):1-5. Available from: https://doi.org/10.1038 /s41467-020-20226-9.

30. Bubar KM, Reinholt K, Kissler SM, Lipsitch M, Cobey S, Grad YH, Larremore DB. Modelinformed COVID-19 vaccine prioritization strategies by age and serostatus. Science. 2021 Feb 26;371(6532):916-921.

31. Roy S, Dutta R, Ghosh P. Optimal time-varying vaccine allocation amid pandemics with uncertain immunity ratios. IEEE Access. 2021 Jan 21;9:1511021.

32. Antal C, Cioara T, Antal M, Anghel I. Blockchain platform for COVID-19 vaccine supply management. IEEE Open Journal of the Computer Society. 2021 Mar 22;2:164-178.

33. Ricci L, Maesa DD, Favenza A, Ferro E. Blockchains for covid-19 contact tracing and vaccine support: A systematic review. IEEE Access. 2021 Mar 2;9:37936-50.

34. Gray KJ, Bordt EA, Atyeo C, Deriso E, Akinwunmi B, Young N, Medina Baez A, Shook LL, Cvrk D, James K, De Guzman R, Brigida S, Diouf K, Goldfarb I, Bebell LM, Yonker LM, Fasano A, Rabi SA, Elovitz MA, Alter G, Edlow AG, COVID-19 vaccine response in pregnant and lactating women: a cohort study, American Journal of Obstetrics and Gynecology (2021), Available from: https:// doi.org/10.1016/j.ajog.2021.03.023.
35. Shimabukuro TT, Kim SY, Myers TR, Moro PL, Oduyebo T, Panagiotakopoulos L, Marquez PL, Olson CK, Liu R, Chang KT, Ellington SR. Preliminary findings of mRNA Covid- 19 vaccine safety in pregnant persons. New England Journal of Medicine. 2021 Jun 17; 384(24): 2273-2282.

36. Karlsson LC, Soveri A, Lewandowsky S, Karlsson L, Karlsson H, Nolvi S, Karukivi M, Lindfelt M, Antfolk J. Fearing the disease or the vaccine: The case of COVID-19. Personality and individual differences. 2021 Apr 1;172:110590. Available from: $\mathrm{h}$ ttps://doi.org/10.1016/j.paid.2020.110590

37. Campos-Outcalt D. ACIP recommendations for COVID-19 vaccines-and more. The Journal of Family Practice. 2021 Mar 1;70(2):86-89.

How to cite this article: Alexander C.A., Wang L., Shah V. Vaccine Hesitancy, Vaccine Acceptance, and Recommendations about the COVID19 Vaccines. Journal of Medical Research and Health Sciences. 2021;1599-1608. https://doi.org /10.52845/JMRHS/2021-4-12-2 